\title{
REGULAÇÃO DE ALIMENTOS NO BRASIL
}

Food regulation in Brazil

${ }^{1}$ Escola Nacional de Saúde Pública. Fundação Oswaldo Cruz. Rio de Janeiro/RJ, Brasil. Correspondência: Rosana Magalhães. E-mail: rosana99@uol.com.br.

Recebido em: 21/09/2015. Revisado em: 09/11/2015. Aprovado em: 10/11/2015. 


\section{RESUMO}

Políticas publicas de alimentação e nutrição são intervenções complexas e mediadas por múltiplos atores e interesses. Agências internacionais, governos, consumidores, empresas e instituições científicas desempenham papéis estratégicos e participam da definição de alternativas na área por meio de diferentes mecanismos e arenas. Desequilíbrios de poder e informação frequentemente exercem forte impacto no processo decisório, tornando-o um ambiente intensamente conflituoso. Nessa perspectiva, este artigo analisa aspectos do desenho e implementação de marcos regulatórios no campo da alimentação e nutrição buscando valorizar tal complexidade e contribuir para a reflexão sobre tensões e desafios presentes no processo de regulação de alimentos no Brasil.

\section{Palavras-Chave:}

Política Pública; Regulação; Segurança Alimentar; Segurança Nutricional.

\section{ABSTRACT}

Public policies on food and nutrition are complex interventions mediated by a variety of actors and interests.International agencies, governments, consumers, private companies and scientific institutions play strategic roles and are engaged in the definition of alternatives through different mechanisms and arenas. Imbalances of power and information have a strong impact on decision making, creating an environment of conflict. From this perspective, the article analyzes the creation and implementation of regulatory frameworks in the area of food and nutrition. The main purpose of this study is contribute to reflection on the tensions and challenges surrounding food regulation in Brazil.

\section{Keywords:}

Food Security; Nutrition Security; Public Policy; Regulation. 


\section{Introdução}

Sabemos que, desde o início do século XX e especialmente após a II Guerra Mundial, a produção de alimentos foi ampliada de maneira significativa e sem precedentes. Podemos dizer que o fantasma da escassez foi afastado e, apesar do crescimento populacional expressivo, avanços tecnológicos e novos arranjos institucionais garantiram a disponibilidade de alimentos em escala global. Paradoxalmente, porém, altos níveis produtivos não resultaram na superação da fome. Para Amartya $\operatorname{Sen}^{1}$, basta interpretar o perfil das relações sociais e os elementos de discriminação presentes em cada sociedade para apreender a natureza da fome contemporânea. Segundo o autor, para explicar a persistência da privação alimentar mesmo em contextos de estabilidade ou aumento da produção de alimentos, é preciso privilegiar a análise das prerrogativas e dos direitos que estruturam as práticas sociais em cada contexto. Na maioria das circunstâncias, tais prerrogativas tornam-se os principais vetores do acesso permanente aos alimentos. Escolaridade, nível de renda, perfil de proteção social, acesso à terra e ao trabalho e uso de equipamentos públicos, por exemplo, tendem a impactar as chances de uma dieta saudável na medida em que, de maneira interdependente, corroboram a maior participação cívica, o compartilhamento de bens e serviços e o enfrentamento de vulnerabilidades ao longo da vida.

Essa abordagem também mostra-se útil para investigar novos problemas e riscos ligados à alimentação, para além da subnutrição. Aprofundando um pouco mais o debate, Contreras $^{2}$ afirma que o temor de que a comida não seja suficiente retrocedeu e, hoje, a preocupação dominante é cada vez mais de caráter qualitativo. Assim, frente às mudanças demográficas - notadamente marcadas pelo envelhecimento da população-, a introdução de novas e, muitas vezes, drásticas tecnologias como a transformação genética e, ainda, o crescimento da obesidade, da diabetes e da hipertensão arterial associado ao consumo de alimentos ricos em sódio, açúcar e gorduras, ganha destaque a chamada "agenda da qualidade". Esta agenda implica reconhecer, portanto, o direito à alimentação saudável e, ao mesmo tempo, a dinâmica de interesses e influências recíprocas que envolve o Estado, o mercado e as comunidades em torno da questão alimentar e nutricional.

No contexto contemporâneo, essa dinâmica tem assumido contornos e significados cada vez mais contraditórios e ambivalentes. Em grande parte, isso se deve ao surgimento de um mercado global relativamente bem integrado, às transformações no processo de industrialização e comercialização de alimentos, às mudanças tecnológicas no campo e à crescente urbanização. De acordo com Lang e Heasman ${ }^{3}$, se tradicionalmente a agricultura dominou a política alimentar e nutricional, hoje as indústrias e empresas que comercializam alimentos processados

\footnotetext{
${ }^{1}$ SEN, A. Poverty and famines. New York: Oxford University Press, 1997.

${ }^{2}$ CONTRERAS CONTRERAS, Jesús. A modernidade alimentar: entre a superabundância e a insegurança. História, Questões e Debates, Curitiba, v. 54, p. 19-45, jan./jun. 2011.

${ }^{3}$ LANG, T; HEASMAN, M. Food wars: the global battle for mouths, minds and markets. London: Earthscan, 2005.
} 
assumem o protagonismo e tendem a impactar enormemente os padrões de produção e consumo de maneira generalizada. Para os autores, através de fortes investimentos em pesquisa sobre fertilizantes, pesticidas e aditivos, de estratégias de gerenciamento voltadas à diminuição de custos e de propaganda, surgiu nas últimas décadas um número relativamente pequeno de corporações com o poder de forjar escolhas alimentares cada vez mais homogêneas em escala global. Tais empresas percebem a política de alimentação e as arenas decisórias na área como partes integrantes de sua estratégia de negócios.

Ao mesmo tempo, os mecanismos tradicionais utilizados pelo Estado para estabelecer parâmetros e operar no monitoramento das políticas públicas tendem a perder força. Com a globalização da economia, o investimento em políticas públicas redistributivas e, consequentemente, em ações voltadas à consolidação de direitos (dentre eles, o direito à alimentação saudável) tende a ser constrangido pela intensa mobilidade do capital em busca de maior rentabilidade e vantagens competitivas. No entanto, como chamam a atenção Rosanvallon ${ }^{4}$ e Gilbert ${ }^{5}$, para além da crise fiscal dos Estados nacionais, o desemprego estrutural, o crescimento da população inativa e as transformações no perfil das famílias e comunidades - gerando maior heterogeneidade e laços mais frágeis de vinculação social - também têm contribuído para a corrosão da cidadania e da efetividade dos regimes de bem-estar. Com isso, o mundo se depara com o desafio da reestruturação da governança local e também global no campo das políticas públicas de corte social. No que se refere especificamente à alimentação e nutrição, coloca-se para os Estados, setores organizados da sociedade civil e população em geral a tarefa de articular distintos interesses e ampliar o debate em torno do alimento não apenas como mercadoria, mas, prioritariamente, como direito humano e demanda social.

Nesse percurso, as experiências são diversas. Para analisar alguns dos principais contornos e perspectivas da regulação de alimentos no caso brasileiro, o artigo apresenta elementos normativos e aspectos relevantes ligados ao papel desempenhado pelos ministérios da Saúde, da Agricultura e do Meio Ambiente na conjuntura recente. Sem a pretensão de esgotar o debate, o objetivo é contribuir para a reflexão sobre os desafios da regulação de alimentos no Brasil.

\section{A política de alimentação e nutrição no Brasil: antecedentes históricos e principais tendências}

A construção da agenda pública e o processo de tomada de decisão política em torno de problemas que afetam a população, como já assinalado anteriormente, são atravessados por múltiplos interesses, disputas e compromissos. Essa natureza

${ }^{4}$ ROSANVALLON, P. La nouvelle question sociale: repenser l'etat-providence. Paris: Éditions du Seuil, 1995. ${ }^{5}$ GILBERT, N. Transformation of the welfare state: the silent surrender of public responsability. New York: Oxford University Press, 2004. 
complexa das ações governamentais e não governamentais frente aos desafios públicos tem mobilizado o debate sobre a conformação das políticas públicas enquanto campo de pesquisa e objeto de estudo. Diferentes matrizes teóricas e tradições disciplinares após os anos 1930 apoiaram a reflexão sobre o tema, introduzindo novos conceitos e perspectivas metodológicas com o objetivo de favorecer a compreensão de variáveis institucionais e do papel de atores sociais no desenho e implementação de estratégias políticas em cada contexto. Com diferentes premissas e alcances explicativos, os modelos de análise têm contribuído para a interpretação de trajetórias marcadas pela incerteza e ambiguidade ${ }^{6}$. Na verdade, essa plasticidade do processo de elaboração de alternativas e soluções para questões públicas configura um dos poucos aspectos consensuais do campo. Apesar das intensas controvérsias em torno do que privilegiar sob o ponto de vista analítico, há o reconhecimento da relevância de um olhar abrangente e plural. Para Kingdon ${ }^{7}$, é preciso ainda distinguir a agenda governamental da agenda decisória, na medida em que nem sempre um tema de interesse do governo é traduzido em uma proposta de intervenção concreta. Crises, surgimento de novas tecnologias ou mudanças administrativas podem tanto favorecer como ofuscar tomadas de posição sobre questões públicas. Ao mesmo tempo, uma vez alcançado o status de problema que merece ser enfrentado, nem sempre os atores políticos compartilham a mesma percepção sobre os caminhos a serem adotados. Com isso, muitas vezes as iniciativas tendem a assumir um caráter mais conservador e subsidiar mudanças menos radicais e incrementais8.

Partindo dessas considerações, é possível perceber que a questão alimentar e nutricional tem ocupado a agenda dos governos brasileiros com ênfases e contornos distintos ao longo da história. Segundo Belik ${ }^{9}$, desde o início do século XX até 1996 (ano da Cúpula Mundial da Alimentação realizada em Roma), as políticas públicas de alimentação e nutrição foram marcadas pela preocupação com a produção agrícola, o abastecimento nas cidades, o controle dos preços e a distribuição de alimentos para grupos sociais específicos. No entanto, em que pese essa tendência em determinadas conjunturas, houve deslocamentos importantes na direção da integração entre as múltiplas iniciativas, da consolidação de projetos institucionais de longo prazo e da criação de um arcabouço legal para balizar a intervenção estatal. Durante o governo Vargas e sob a forte influência do médico e geógrafo Josué de Castro, foram criados a Sociedade Brasileira de Alimentação (SBA), o Serviço de Alimentação da Previdência Social (SAPS), o Serviço Técnico de Alimentação Nacional (STAN) e a Comissão

${ }^{6}$ SOUZA, C. Estado da arte da pesquisa em políticas públicas. In: HOCHMAN, G.; ARRETCHE, M.; MARQUES, E. (Orgs.). Políticas públicas no Brasil. Rio de Janeiro: Fiocruz, 2007. p. 65-86.

${ }^{7}$ KINGDOM, J.W. Agendas, alternatives and public choices. New York: Longman, 2003.

${ }^{8}$ LINDBLOM, C. E.; WOODEHOUSE, E. J. The policy: making process. New Jersey: Prentice Hall, 1993.

${ }^{9}$ BELIK, W. Perspectivas para a segurança alimentar e nutricional no Brasil. Saúde e Sociedade, v. 12, n. 1, p. 12-20, jan./jun. 2003. Disponível em: <http://www.scielo.br/pdf/sausoc/v12n1/04.pdf>. http://dx.doi.org/10.1590/S0104-12902003000100004. 
Nacional de Alimentação (CNA $)^{10}$. Tais instituições governamentais e fóruns públicos tiveram como principais objetivos a melhoria das condições de alimentação dos trabalhadores urbanos, o aprimoramento tecnológico e a ampliação de pesquisas sobre alimentos e padrões nutricionais no país. Na década de 1950, Josué de Castro, através da CNA, contribuiu para a formulação do Plano Nacional de Alimentação, que visava ao equacionamento da fome no país, o estímulo ao desenvolvimento de ações regionalizadas e o apoio à inovação tecnológica. Talvez o maior mérito da CNA tenha sido o esforço de alargar o conjunto de agências e setores envolvidos na questão alimentar e nutricional, favorecendo um olhar mais abrangente sobre ações e iniciativas prioritárias. No âmbito do Plano Nacional de Alimentação, foram elaboradas propostas exitosas, como a programa de merenda escolar.

No entanto, como observou L'Abbate

os programas de alimentação e nutrição passam a depender, para sua execução, da ação conjunta de várias instituições, que por sua vez se emaranham numa complexidade de trâmites burocráticos, tornando muitas vezes tortuoso o caminho a ser percorrido ${ }^{11}$.

De fato, a CNA, antes ligada ao Conselho Federal de Comércio Exterior, em 1951 foi transferida para o então Ministério da Educação e Saúde, e sua função como o órgão responsável pela política de alimentação no país foi sendo fragilizada ao longo das décadas seguintes. Na verdade, o período pós-1964 foi marcado pela centralização decisória, pela fragilização dos mecanismos de controle social e por estratégias conservadoras que impactaram o conjunto de políticas sociais. Dentre as intervenções anteriores na área de alimentação e nutrição, apenas o Programa Nacional de Merenda Escolar ganhou sustentabilidade graças ao apoio do Fundo das Nações Unidas para a Infância (Unicef). Em 1972, a CNA foi extinta e, por meio da Lei n. 5.829, foi criado o Instituto Nacional de Alimentação e Nutrição (INAN), vinculado ao Ministério da Saúde. Sob o impacto dos dados sobre condições de saúde e nutrição do Estudo Nacional de Despesas Familiares (ENDEF) desenvolvido entre 1974 e 1975 pelo Instituto Brasileiro de Geografia e Estatística (IBGE), o INAN instituiu o Programa Nacional de Alimentação e Nutrição (Pronan), um conjunto de ações e intervenções considerado como marco na trajetória das iniciativas governamentais na área. De acordo com Silva ${ }^{12}$, especialmente o II Pronan integrou iniciativas de suplementação alimentar para grupos com carências específicas, racionalização dos sistemas de produção e comercialização de alimentos e múltiplas atividades voltadas à melhoria do quadro nutricional da população brasileira envolvendo apoio a pesquisa e avaliação. No entanto, apesar de sua abrangência e

\footnotetext{
${ }^{10}$ MAGALHÃES, R. Fome: uma (re)leitura de Josué de Castro. Rio de Janeiro: Fiocruz, 1997.

${ }^{11}$ L'ABBATE, S As políticas de alimentação e nutrição no Brasil: I. Período de 1940 a 1964. Revista Nutrição PUCCAMP, v. 1, n. 2, p. 87-138, jul./dez. 1988.

${ }^{12}$ SILVA, Alberto Carvalho da. De Vargas a Itamar: políticas e programas de alimentação e nutrição. Estudos Avançados, São Paulo, v. 9, n. 23, jan./abr. 1995. Disponível em: <http://www.scielo.br/pdf/ea/v9n23/ v9n23a07.pdf>. http://dx.doi.org/10.1590/S0103-40141995000100007.
} 
robustez, essa política também enfrentou o desafio da articulação de múltiplas empresas e agências governamentais. Em um contexto político marcado pela intransparência da gestão pública, algumas intervenções foram deslocadas para outros Ministérios ou foram vinculadas diretamente à Presidência da República. Problemas ligados à baixa capacidade administrativa, à ineficiência no uso de recursos e à hipertrofia burocrática comprometeram o alcance de resultados, e várias ações foram descontinuadas.

Além disso, até o final da década de 1980 a questão da qualidade dos alimentos não ocupou um espaço relevante na formatação das políticas de alimentação e nutrição. Esse panorama começou a ser transformado a partir da divulgação de informes técnicos da Organização das Nações Unidas para Agricultura e Alimentação (FAO) sobre o tema e, principalmente, no bojo do amplo debate entre governos e associações civis realizado em 1996 durante a Conferência Mundial de Alimentação em Roma. Na ocasião, as perspectivas da segurança alimentar e nutricional e do direito humano à alimentação foram aprimoradas e a questão da qualidade dos alimentos consumidos ganhou foco na agenda política global. O documento formulado pelo governo brasileiro para subsidiar a participação do país na Conferência seguiu essa importante tendência:

Segurança alimentar e nutricional consiste em garantir a todos condições de acesso a alimentos básicos, seguros e de qualidade, em quantidade suficiente, de modo permanente e sem comprometer o acesso a outras necessidades essenciais, com base em práticas alimentares saudáveis, contribuindo assim para uma existência digna em um contexto de desenvolvimento integral da pessoa humana ${ }^{13}$.

Na verdade, após o processo de impeachment do governo Collor em 1992, a redução de $64 \%$ nos recursos orçamentários destinados a programas nutricionais em relação a 1990 e a divulgação do Mapa da Fome pelo Instituto de Pesquisas Econômicas e Aplicadas (Ipea), houve no país uma grande mobilização social em torno dos direitos sociais e contra a fome. Em 1993, a Ação da Cidadania contra a Fome e a Miséria e pela Vida representou esse esforço voltado à criação de múltiplas arenas de participação coletiva e parcerias entre instituições civis e agências estatais ${ }^{14}$. No mesmo ano foi criado, já no novo governo (de Itamar Franco), o Conselho Nacional de Segurança Alimentar e Nutricional (Consea) - composto por representantes da sociedade civil e ministérios e orientado para o enfrentamento de problemas tradicionais na área como, a fragmentação institucional, a superposição das ações e a baixa efetividade. O Consea incentivou a realização da I Conferência Nacional de Segurança Alimentar e Nutricional, um marco importante na consolidação de uma abordagem

\footnotetext{
${ }^{13}$ BRASIL. Comitê Nacional para a Cúpula Mundial de Alimentação. Brasília. (DF): Ministério das Relações Exteriores; 1996. Disponível em: <http://www.fao.org/docrep/003/W3613P/W3613P00.htm>. Acesso em: 02 ago. 2015.

${ }^{14}$ MAGALHÃES, R. Enfrentando a pobreza, reconstruindo vínculos sociais: as lições da Ação da Cidadania contra a Fome, a Miséria e pela Vida. Cad Saude Pública, Rio de Janeiro, v. 18, suppl., p. 121-137, 2002. Disponível em: <http://www.scielo.br/pdf/csp/v18s0/13799.pdf>. http://dx.doi.org/10.1590/S0102-311X2002000700013.
} 
abrangente sobre os problemas nutricionais no país. Nessa conjuntura, a delegação brasileira que participou da Cúpula Mundial da Alimentação organizada pela FAO em 1996 na cidade de Roma consolidou a visão da segurança alimentar e nutricional como dimensão indissociável do direito humano à alimentação adequada e contribuiu para o desenho das ações no contexto nacional. O Consea e o debate internacional estimularam ainda a criação, em 1998, do Fórum Brasileiro de Segurança Alimentar e Nutricional no Brasil, entidade que reuniu organizações da sociedade civil, movimentos sociais e grupos envolvidos com a temática nos diferentes estados e municípios. Tratava-se, assim, de uma iniciativa voltada à dinamização da participação social e ao engajamento das comunidades para melhorar o desempenho dos governos na área.

Dessa forma, durante a década de 1990 a grande mobilização social contra a privação alimentar foi associada à valorização da qualidade dos alimentos consumidos, com uma abordagem mais ampla e intersetorial. Houve também importantes avanços no que se refere à legislação e à estruturação da ação governamental nos diferentes níveis de gestão. A Lei Orgânica de Segurança Alimentar e Nutricional ${ }^{15}$ (Losan) e o Sistema de Segurança Alimentar e Nutricional (Sisan), instituídos em 2006, revelam o vigor dessa trajetória e a presença do tema da segurança alimentar e nutricional na agenda política. No entanto, como aponta Burlandy ${ }^{16}$, ainda é difícil consolidar um sistema de monitoramento e financiamento integrados. Visões antagônicas sobre, por exemplo, a comercialização de transgênicos ou o uso de agrotóxicos persistem e colaboram para o baixo nível de consenso entre ministérios, setores privados e organizações não governamentais. Evidentemente tais divergências impactam o processo de aprimoramento dos instrumentos de regulação e fiscalização.

\section{Regulação de alimentos no Brasil: competências, responsabilidades e dilemas}

A regulação de alimentos pode ser entendida como o estabelecimento de regras para a rotulagem e composição de alimentos processados, divulgação e propaganda de alimentos e manutenção da qualidade em todas as etapas da cadeia produtiva e nos locais de consumo. Recentemente, a questão da sustentabilidade tem sido agregada ao debate à medida que crescem as evidências sobre os impactos e efeitos perversos do processo de produção e distribuição de alimentos no meio ambiente. A contaminação e o desperdício da água, o gasto excessivo de energia, a acumulação de resíduos tóxicos no solo tornam-se, dessa maneira, elementos da

\footnotetext{
${ }^{15}$ BRASIL. Lei n. 11.346, de 15 de setembro de 2006. Cria o Sistema Nacional de Segurança Alimentar e Nutricional - SISAN com vistas em assegurar o direito humano à alimentação adequada e dá outras providências. Disponível em: <http://www.planalto.gov.br/ccivil_03/_ato2004-2006/2006/lei/l11346.htm>. Acesso em: 31 jan. 2017.

${ }^{16}$ BURLANDY, L. A construção da política de segurança alimentar e nutricional no Brasil: estratégias e desafios para a promoção da intersetorialidade no âmbito federal de governo. Ciên. e saúde coletiva, v. 14, n. 3, p. 851-860, jun. 2009. Disponível em: <http://www.scielo.br/scielo.php?script=sci_arttext\&pid =S1413-81232009000300020>. http://dx.doi.org/10.1590/S1413-81232009000300020.
} 
cadeia produtiva que merecem cada vez mais um monitoramento criterioso e permanente. Além disso, a regulação de alimentos tem sido apontada como uma maneira eficaz de garantir escolhas bem informadas. Nos últimos anos, foram constituídos padrões e diretrizes internacionais para subsidiar os governos e melhorar o acesso do consumidor a informações relevantes para uma dieta saudável e sustentável. O Codex Alimentarius, aprovado pela FAO em 1963, tornou-se uma referência mundial para a rotulagem de alimentos. Além de favorecer a disponibilização de informações sobre os nutrientes presentes no alimento, o Codex também contribuiu para balizar as alegações de saúde, ou seja, os possíveis efeitos benéficos associados ao consumo de determinado produto desde que comprovados cientificamente ${ }^{17}$. Em 1981, a Organização Mundial da Saúde (OMS) e o Unicef divulgaram o International Code of Marketing of Breast-Milk Substitutes com o objetivo de estimular o aleitamento materno e, ao mesmo tempo, garantir práticas apropriadas de substituição ao leite materno, evitando a propaganda abusiva de fórmulas lácteas nos serviços de saúde. No entanto, como vimos anteriormente, a preocupação com a qualidade e a regulação de alimentos é recente na maioria das sociedades. A OMS, ao lançar a Global Strategy on Diet, Physical and Health em maio de 2004, assinalou a importância da regulação da propaganda de alimentos para crianças, mas revelou a tendência de enfraquecimento do papel dos governos na formulação e implementação de medidas restritivas.

Nesse cenário, têm prevalecido mecanismos de autorregulação do mercado e iniciativas ainda pouco efetivas. De acordo com a $\mathrm{OMS}^{18}$, a baixa efetividade das intervenções e o aumento do risco de doenças associadas ao consumo de alimentos têm ameaçado a confiança nos governos e instituições científicas. Casos como o da contaminação da ração de animais por dioxina registrada na Bélgica em 1999, que foi espalhada por mais de 1.500 fazendas em toda a Europa por duas semanas antes que o problema recebesse a devida atenção, alertaram o mundo para a gravidade do problema. Nos Estados Unidos, surtos de Escherichia coli em hambúrgueres e de Salmonella em ovos, por exemplo, revelaram os efeitos colaterais da debilidade das estruturas de regulação e fiscalização das múltiplas dimensões da produção e consumo de alimentos. Mas, frente às novas ameaças, surgem também alternativas de enfrentamento. A preocupação com a natureza e o escopo da regulação de alimentos tem contribuído para a criação de novos espaços de ação. No Reino Unido, a responsabilidade pelo controle da qualidade dos alimentos foi transferida do Ministry of Agriculture, Fisheries and Food (Ministério da Agricultura, Pesca e Alimentação) para um novo órgão com maior autonomia, nomeado Food Standards Agency (Agência de Padrões

${ }^{17}$ COUTINHO, J. G.; RECINE, E. Experiências internacionais de regulamentação das alegações de saúde em rótulos de alimentos. Rev Panam Salud Publica, Pan Am J Public Health, v. 22, n. 6, 2007. Disponível em: <http://www. scielosp.org/pdf/rpsp/v22n6/a12v22n6.pdf>. http://dx.doi.org/10.1590/S1020-49892007001100012.

${ }^{18}$ WORLD HEALTH ORGANIZATION (WHO). Food and health in Europe: a new basis for action. WHO Regional Publications, European Series n. 86, 2004. 
Alimentares). O grande desafio na maioria dos países tem sido evitar que um setor do governo seja responsável ao mesmo tempo por regular a qualidade dos alimentos consumidos e promover os interesses das indústrias. Para Houghton et al ${ }^{19}$, o cenário atual impõe, dessa forma, a implementação de mecanismos políticos de regulação que garantam transparência, participação social e accountability.

No Brasil, essa discussão também tem ocupado a agenda pública recente. O Consea, reinstituído em 2003 e atualmente composto por 38 representantes da sociedade civil e 19 ministros de governo, tem a função de elaborar propostas e contribuir para monitorar iniciativas públicas de segurança alimentar e nutricional, incluindo as ações de regulação. No âmbito do Consea, foram intensificados os debates sobre a natureza dos marcos legais da segurança alimentar e nutricional que culminaram na aprovação da Lei n. $11.346 / 2006^{20}$, que instituiu o Sistema Nacional de Segurança Alimentar e Nutricional (Sisan). Nesse percurso, é importante ainda destacar a inclusão do direito humano à alimentação na Constituição brasileira - na Emenda Constitucional n. 64/2010 $0^{21}$ - e o detalhamento dos múltiplos componentes e arenas decisórias do Sisan, integrando os diferentes entes federativos. No que se refere à regulação de alimentos, no âmbito do Consea foi criado um grupo de trabalho (GT) com a perspectiva de fortalecer essa atividade e dar visibilidade ao processo de implementação das ações. Assim, de acordo com o texto elaborado pelo GT, a regulação de alimentos no Brasil inclui a restrição da publicidade de alimentos para o público infantil, o aprimoramento e a fiscalização da rotulagem com o objetivo de tornar a informação o mais clara possível para os consumidores e, também, a revisão dos ingredientes e aditivos alimentares a fim e garantir os padrões de qualidade esperados ${ }^{22}$. No entanto, o Consea é um órgão de caráter consultivo e, portanto, para compreender a rede de competências e responsabilidades em torno da regulação de alimentos no País, é necessário refletir sobre o papel de diferentes instituições e agências estatais.

O Brasil acompanha normas internacionais na área - como o Codex Alimentarius, no que tange à rotulagem -, mas também estabelece regras e parâmetros específicos para a avaliação da qualidade dos alimentos produzidos e comercializados. Um número considerável de ministérios e agências estatais é responsável pela regulação de alimentos e, neste aspecto, o arcabouço normativo é complexo e, muitas vezes,

\footnotetext{
${ }^{19 H O U G H T O N, ~ J . ~ R . ; ~ R O W E, ~ G ; ~ F R E W E R, ~ L . ~ J . ; ~ K L E E F, ~ E . V . ; ~ C H R Y S S O C H O I D I S, ~ G ; ~ K E H A G I A, ~ O . ; ~ K O R Z E N-B O H R, ~}$ S.; LASSEN, J.; PFENNING, U.; STRADA, A. The quality of food risk management in Europe:perspectives and priorities. Food Policy, v. 33, p. 13-26, 2008.

${ }^{20}$ BRASIL. Lei n. 11.346, de 15 de setembro de 2006, cit.

${ }^{21}$ BRASIL. Emenda Constitucional n. 64, de 15 de setembro de 2006. Altera o art. $6^{\circ}$ da Constituição Federal, para introduzir a alimentação como direito social. Disponível em: <http://www.planalto.gov.br/ccivil_03/ Constituicao/Emendas/Emc/emc64.htm>. Acesso em: 31 jan. 2017.

${ }^{22}$ CONSEA. Regulação de alimentos: garantia de segurança alimentar e nutricional. Texto elaborado pelo Grupo de Trabalho de Regulação de Alimentos Comissão Permanente 7-Consumo, Nutrição e Educação. Disponivel em: <http://www4.planalto.gov.br/consea/eventos/conferencias/5a-conferencia-nacional-deseguranca-alimentar-e-nutricional/documentos-da-5deg-conferencia/regulacao-de-alimentos.pdf $>$.
} 
contraditório. Sem a pretensão de esgotar essa discussão, podemos afirmar que, dentre as instâncias existentes no país, o Ministério da Saúde (MS), o Ministério da Agricultura, Pecuária e Abastecimento (MAPA) e o Ministério do Meio Ambiente (MMA) atuam de maneira privilegiada na regulação de alimentos. O MAPA é responsável pela qualidade de alimentos de origem animal, frutas, legumes, grãos, sementes e outros insumos, além de ração animal. No que se refere ao abate de animais, o MAPA - por meio da Instrução Normativa n. 3/2000 23 instituiu requisitos mínimos para garantir a proteção dos animais e a implementação de métodos de insensibilização eficazes e menos cruéis. Mas sabemos que, ainda hoje, cerca de 30\% dos abatedouros no Brasil não são adequadamente fiscalizados e, além do sofrimento dos animais, contaminações de origem física, química e biológica são frequentes.

O Ministério da Saúde, através da Agência Nacional de Vigilância Sanitária (Anvisa), criada pela Lei n. 9.782/199924, tem um papel de destaque por ser responsável pela elaboração e aplicação de regras para a rotulagem nutricional, pela revisão das estratégias de propaganda e pelo controle de qualidade de alimentos processados e industrializados. No que se refere aos chamados alimentos funcionais, a Anvisa divulgou, em 1999, diferentes resoluções visando a garantir a segurança e a confiabilidade das alegações de propriedades funcionais informadas nos rótulos de alimentos. Em 2005, uma lista de alegações relacionadas à cafeína, ao sorbitol, xilitol, manitol, estearato de sódio, ômega 6 e ácidos graxos monoinsaturados e poli-insaturados foram suprimidas.

Já o MMA, com a missão de garantir o uso sustentável dos recursos ambientais para a promoção do desenvolvimento humano e social e a proteção da biodiversidade, tem várias atribuições conectadas com a realização do direito à alimentação saudável. O MMA, por exemplo, deve avaliar as condições da liberação de cultivo e comercialização de organismos geneticamente modificados ou transgênicos e, também, os agrotóxicos destinados ao uso em ambientes hídricos, florestas nativas e outros ecossistemas e seus impactos no meio ambiente.

No entanto, nem sempre essas fronteiras estão totalmente preservadas. Além disso, existem ainda outras instâncias cujas atribuições também envolvem aspectos substantivos do processo de regulação de alimentos. A propaganda de alimentos para o público infantil, por exemplo, pode envolver a Anvisa, o Código de Defesa do Consumidor e o Conselho Nacional de Direitos da Criança e Adolescente (Conanda). Arenas intersetoriais e interinstitucionais, com presença de organizações civis e representantes das indústrias, também estão previstas em dispositivos e marcos legais. Assim, apesar dos inegáveis avanços obtidos no processo de consolidação

\footnotetext{
${ }^{23}$ MINISTÉRIO DA AGRICULTURA E DA PECUÁRIA. Instrução Normativa n. 3, de 17 de janeiro de 2000. Disponivel em: <http://extranet.agricultura.gov.br/sislegis-consulta/consultarLegislacao.do?operacao=vi sualizar\&id=1793>. Acesso em: 31 jan. 2017.

${ }^{24}$ BRASIL. Lei n. 9.782, de 26 de janeiro de 1999. Define o Sistema Nacional de Vigilância Sanitária, cria a Agência Nacional de Vigilância Sanitária, e dá outras providências. Disponível em: <http://www.planalto. gov.br/ccivil_03/leis/L9782.htm>. Acesso em: 31 jan. 2017.
} 
de estruturas de governança na área, disputas e conflitos são frequentes e podem ocupar espaços institucionais pouco articulados e híbridos.

\section{Experiências, aprendizados e desafios}

Existem evidências científicas robustas de que o consumo de gordura trans - um tipo específico de gordura formado por um processo de hidrogenação natural em carnes e leite ou artificial, a partir de técnicas industriais, tende a aumentar o risco de cardiopatias e acidente vascular cerebral. Vários países têm estabelecido normas e parâmetros rígidos para evitar o consumo dessa substância. Nos alimentos in natura de origem animal, a quantidade de gordura trans tende a ser desprezível, mas ela aumenta sensivelmente em sorvetes, batatas fritas, pipocas, bolos, biscoitos e outros produtos industrializados na medida em que melhoram a consistência, a aparência e o tempo de conservação desses produtos. Em 2003, a Dinamarca estabeleceu o limite de $2 \%$ de gordura trans no total de gordura dos alimentos comercializados. Seguindo essa experiência pioneira, seis países europeus praticamente baniram a gordura trans e, em 16 de junho deste mesmo ano, o Food and Drugs Administration (FDA), órgão responsável pela regulação de alimentos e medicamentos nos Estados Unidos, definiu o prazo de 3 anos para a indústria implementar mudanças nesse sentido. Assim, embora não exista recomendação de ingestão diária de gordura trans, a OMS sugere que o consumo máximo não ultrapasse 2 gramas por dia, ou 1\% do total calórico diário. No Brasil, a Anvisa determinou em 2006 que a presença de gordura trans fosse identificada no rótulo dos alimentos industrializados. No ano seguinte, a agência reguladora estabeleceu os limites de $5 \%$ de gordura trans do total de gorduras em alimentos industrializados e de $2 \%$ do total de gorduras em óleos e margarinas. De acordo com a Resolução da Diretoria Colegiada (RDC) n. 359, alimentos industrializados que contenham até 0,2 grama de gordura trans por porção podem incluir na rotulagem a informação "não contém trans". Como analisam Proença e Silveira ${ }^{25}$, essa alternativa cria a possibilidade de consumo de quantidades expressivas de gordura trans caso o consumidor faça a ingestão de mais de uma porção do produto. Para as autoras "observa-se uma fragilidade importante na legislação brasileira, pois a indicação de ausência de gordura trans na informação nutricional não pode ser tida como segura”. Apesar de o Ministério da Saúde e a Associação Brasileira de Indústrias de Alimentos (Abia) terem promovido acordos para adequar a produção aos limites mais próximos de normas praticadas em outros países, não existe data prevista para que os alimentos industrializados possam ser considerados livres de gorduras trans no país.

A redução do teor de sódio nos alimentos também está fortemente relacionada ao controle de problemas de saúde como cardiopatias, hipertensão arterial e

${ }^{25}$ PROENÇA, R. P. da C.; SILVEIRA, B. M. Recomendações de ingestão e rotulagem de gordura trans em alimentos industrializados brasileiros: análise de documentos oficiais. Rev. Saúde Pública, São Paulo, v. 46, n. 5, out. 2012. Disponível em: <http://www.scielo.br/pdf/rsp/v46n5/20.pdf>. http://dx.doi.org/10.1590/S0034-89102012000500020. 
insuficiência renal. A OMS recomenda o limite de 2 gramas de sódio ou 5 gramas de sal ao dia. No Brasil, o consumo de sódio ultrapassa $100 \%$ desta meta. Desde 2009, a Anvisa monitora a quantidade de sódio nos alimentos industrializados consumidos no país, e o primeiro acordo entre o Ministério da Saúde e representantes das indústrias de alimentos para a redução dos níveis praticados foi formalizado em 2011. No entanto, como destacam Martins, Andrade e Bandoni,

as metas estabelecidas para a redução dos teores de sódio são tímidas e não exigem relevantes modificações na composição dos alimentos processados, apenas favorecem a redução dos teores máximos de cada categoria encontrada no mercado ${ }^{26}$.

Além disso, de acordo com os autores, o monitoramento realizado pela Anvisa é frágil, comprometendo os objetivos de redução dos riscos e promoção da alimentação saudável.

Outra dimensão importante das políticas regulatórias, a propaganda de alimentos também expressa os enfrentamentos entre as distintas esferas de competência e a dinâmica dos conflitos de interesse na área. De acordo com Lang e Heasman ${ }^{27}$, em 2005 as indústrias de alimentos possuíam um orçamento global de 40 bilhões de dólares destinado à propaganda, ou seja, um valor superior ao Produto Interno Bruto (PIB) de cerca de $70 \%$ das nações no período. Em grande parte, esse investimento em marketing tem contribuído para o aumento do consumo de alimentos com maior densidade calórica e ricos em sódio, açúcares e gorduras - e, consequentemente, para a epidemia de obesidade. Há um razoável consenso de que crianças e adolescentes representam o grupo mais vulnerável à propaganda de alimentos industrializados, fast food e bebidas prontas e, frente a esse quadro, vários países fazem severas restrições à exibição de comerciais durante a programação televisiva destinada ao público infantil. No Brasil, uma proposta de regulação da propaganda de alimentos considerados não saudáveis foi encaminhada em 2006 pela Anvisa, através de processo de Consulta Pública n. 71. Após um longo e intenso embate jurídico, técnico e político, em 2010 foi publicada a RDC n. $24^{28}$, considerada um documento importante para o processo de regulação da propaganda de alimentos no país na medida em que tornava obrigatória a divulgação de alertas publicitários sobre riscos à saúde ligados ao consumo de alimentos de baixo teor nutricional. Apesar de omitir aspectos mais amplos do debate - como, por

\footnotetext{
${ }^{26}$ MARTINS, A. P. B.; ANDRADE, G. C.; BANDONI, D. H. Avaliação do monitoramento do teor de sódio em alimentos: uma análise comparativa com as metas de redução voluntárias no Brasil. Revista Visa em Debate, v. 3, n. 2, p. 56-64, 2015. Disponível em: <https://visaemdebate.incqs.fiocruz.br/index.php/ visaemdebate/article/view/323/218>. DOI: 10.3395/2317-269x.00323.

${ }^{27}$ LANG, T; HEASMAN, M. op. cit.

${ }^{28}$ AGÊNCIA NACIONAL DE VIGILÂNCIA SANITÁRIA. Resolução de Diretoria Colegiada n. 24, de 8 de junho de 2015. Dispõe sobre o recolhimento de alimentos e sua comunicação à Anvisa e aos consumidores. Disponível em: <http://portal.anvisa.gov.br/documents/10181/2968795/RDC_24_2015_COMP.pdf/dOd99450-1152-4f7a91b9-1130fcb17fa2>. Acesso em: 31 jan. 2017.
} 
exemplo, a natureza dos mecanismos para controlar a publicidade infantil -, foi incluída a proibição da distribuição de amostras grátis, cupons de desconto e degustações envolvendo alimentos considerados não saudáveis.

Segundo o Instituto Brasileiro de Defesa do Consumidor (Idec) "ao propor regular a propaganda de alimentos, a Anvisa impactaria ao mesmo tempo dois setores poderosos da economia: a indústria de alimentos e a indústria da propaganda"29. No entanto, fortes pressões da Abia e de outras instituições ligadas ao setor contribuíram para a suspensão da resolução e, ainda em 2010, a Advocacia Geral da União (AGU) concluiu que a Anvisa não teria a competência necessária para regular a propaganda de alimentos. Para Henriques, Dias e Burlandy ${ }^{30}$, o fato evidenciou o descompasso entre o debate nacional e internacional sobre o tema. Embora a Resolução n. 163/2014 ${ }^{31}$ do Conanda tenha regulamentado os critérios de enquadramento da propaganda abusiva a serem aplicados pelo Código de Defesa do Consumidor, ainda não há uma lei federal que regule a propaganda de alimentos considerados de baixo teor nutricional ou nocivos à saúde por conter altas quantidades de açúcares, gorduras e sódio. O Idec e o Instituto Alana manifestaram o descontentamento com a interpretação de que a Anvisa deveria se concentrar apenas na informação ao consumidor e reafirmaram o papel regulador da agência estatal. Em 2014, ano em que todos os governos da América Latina firmaram compromisso com o Plano de Ação para a Prevenção da Obesidade em Crianças e Adolescentes, ambas as instituições assinaram a Declaración de Consumers International - Oficina para América Latina y el Caribe, documento baseado na aliança entre entidades de defesa do consumidor da região e em evidências sobre o crescimento de obesidade e sobrepeso associados ao consumo de produtos de baixo teor nutricional.

No que se refere à questão dos agrotóxicos, várias iniciativas governamentais e societárias têm buscado avançar na definição de novos parâmetros e estratégias de regulação. Sabemos que os agrotóxicos podem contribuir para o aumento da disponibilidade de alimentos na medida em que favorecem o controle de pragas com custos relativamente mais baixos. No entanto, como salienta Alves Filho ${ }^{32}$, essas substâncias apresentam efeitos nocivos à saúde humana e ao meio ambiente. Um dos maiores riscos do uso indiscriminado de agrotóxicos é o desenvolvimento concomitante de

\footnotetext{
${ }^{29}$ MARTINS, A. P. B. (Org.). Publicidade de alimentos não saudáveis: os entraves e as perspectivas de regulação no Brasil. São Paulo: Instituto Brasileiro de Defesa do Consumidor - Idec, 2014. (Cadernos Idec - Série Alimentos, v. 2). ${ }^{30}$ HENRIQUES, P.; DIAS, P. C.; BURLANDY, L. A regulamentação da propaganda de alimentos no Brasil: convergências e conflitos de interesses. Cad. Saúde Pública, Rio de Janeiro, v. 30, n. 6, p. 1219-1228, jan./jun. 2014. <http://www. scielo.br/pdf/csp/v30n6/0102-311X-csp-30-6-1219.pdf>. http://dx.doi.org/10.1590/0102-311X00183912.

${ }^{31}$ CONSELHO NACIONAL DOS DIREITOS DA CRIANÇA E DO ADOLESCENTE. Resolução $n$. 163, de 13 de março de 2014. Dispõe sobre a abusividade do direcionamento de publicidade e de comunicação mercadológica à criança e ao adolescente. Disponível em: <http://pesquisa.in.gov.br/imprensa/jsp/visualiza/index.jsp?j ornal=1\&pagina=4\&data=04/04/2014>. Acesso em: 31 jan. 2017.

${ }^{32}$ ALVES FILHO, J. P. Uso de agrotóxicos no Brasil: controle social e interesses corporativos. São Paul: Annablume; FAPESP, 2002.
} 
resistência genética, fazendo com que as aplicações voltadas ao controle de pragas sejam cada vez mais frequentes e concentradas, com impactos socioambientais dramáticos.

A Lei Federal n. 7.802/1989³3, regulamentou o controle, a comercialização e o uso desses produtos no País. No ano seguinte, o Instituto Brasileiro de Meio Ambiente e dos Recursos Naturais Renováveis (Ibama, autarquia federal vinculada ao MMA), através da Portaria n. 349, de 14 de março de 1990, tornou-se o órgão responsável pala avaliação ambiental do uso de agrotóxicos destacando a análise da mutagenicidade, carcinogenicidade e teratonicidade, além das questões ligadas à comunicação de riscos por meio de rotulagem, bula e propaganda. No âmbito da Anvisa, em 2001 foi criado o Programa de Análise de Resíduos de Agrotóxicos em Alimentos (PARA) por meio da RDC n. 119/2003 ${ }^{34}$, com o objetivo de conformar um fluxo permanente de avaliação da qualidade dos alimentos consumidos em relação à presença de agrotóxicos (sobretudo identificando os casos de contaminação acima dos limites permitidos). Em 4 de janeiro de 2002, o Decreto n. $4.074^{35}$ instituiu o Comitê Técnico de Assessoramento para Agrotóxicos, formado por dois representantes do MAPA, do MS e do MMA. Assim, a partir desse decreto, esses ministérios, de acordo com suas respectivas competências, foram responsabilizados pelo estabelecimento de diretrizes para o registro e a utilização de agrotóxicos no país.

Mas, em que pese esses avanços, em 2012 a Associação Brasileira de Saúde Coletiva (Abrasco) publicou um extenso e preocupante dossiê sobre os impactos dos agrotóxicos na saúde no país, considerado o maior mercado de agrotóxicos do mundo. De acordo com o dossiê, um terço dos alimentos consumidos estava contaminado por agrotóxicos, sendo que especialmente as culturas agrícolas de pimentão, morango, pepino, alface e cenoura apresentavam os níveis mais altos dessas substâncias. Além disso, apesar de proibidos na União Europeia e nos Estados Unidos, alguns agrotóxicos continuavam sendo amplamente utilizados na produção agrícola nacional. Os especialistas também destacam os efeitos dos agrotóxicos na potabilidade da água, e as portarias do Ministério da Saúde sobre o assunto divulgadas ao longo dos últimos anos revelam o aumento dos níveis de tolerância com a presença

\footnotetext{
${ }^{33}$ BRASIL. Lei Federal n. 7.802, de 11 de julho de 1989. Dispõe sobre a pesquisa, a experimentação, a produção, a embalagem e rotulagem, o transporte, o armazenamento, a comercialização, a propaganda comercial, a utilização, a importação, a exportação, o destino final dos resíduos e embalagens, o registro, a classificação, o controle, a inspeção e a fiscalização de agrotóxicos, seus componentes e afins, e dá outras providências. Disponível em: <http://www.planalto.gov.br/ccivil_03/leis/L7802.htm>. Acesso em: 31 jan. 2017.

${ }^{34}$ AGÊNCIA NACIONAL DE VIGILÂNCIA SANITÁRIA. Resolução da Diretoria Colegiada n. 119, de 19 de maio de 2003. Criar o PROGRAMA DE ANALISE DE RESÍDUOS DE AGROTÓXICOS EM ALIMENTOS - PARA. Disponível em: <http://portal.anvisa.gov.br/documents/33880/2568070/RDC_119_2003.pdf/7a0276fd-1f65-4191934b-95b13618f383>. Acesso em: 31 jan. 2017.

${ }^{35}$ BRASIL. Decreto n. 4.074, de 4 de janeiro de 2002. Regulamenta a Lei $n^{\circ} 7.802$, de 11 de julho de 1989, que dispõe sobre a pesquisa, a experimentação, a produção, a embalagem e rotulagem, o transporte, o armazenamento, a comercialização, a propaganda comercial, a utilização, a importação, a exportação, o destino final dos resíduos e embalagens, o registro, a classificação, o controle, a inspeção e a fiscalização de agrotóxicos, seus componentes e afins, e dá outras providências. Disponível em: <http://www.planalto. gov.br/ccivil_03/decreto/2002/d4074.htm>. Acesso em: 31 jan. 2017.
} 
dessas substâncias e outros poluentes. Ao mesmo tempo, a pulverização aérea de agrotóxicos - uma prática considerada extremamente nociva ao meio ambiente, de acordo com evidências internacionais - não foi proibida na legislação federal. Nesse cenário, de acordo com Carneiro et al.

a ANVISA desenvolve um processo de avaliação e de informação com o qual busca atender aos aspectos de proteção à saúde pública, mas não é adequadamente apoiada pelo conjunto dos demais órgãos governamentais, o que dificulta sua ação em prol do efetivo controle dos efeitos nocivos do uso de agrotóxicos ${ }^{36}$.

A regulação sobre alimentos transgênicos também é atravessada por interesses mercadológicos e visões conflitantes sobre a natureza dos riscos envolvidos. De acordo com Camara, Nodari e Guilam ${ }^{37}$, até o ano de 2003 o Brasil foi refratário à introdução de sementes transgênicas. Nos anos seguintes, porém, foram editadas três medidas provisórias que foram desdobradas em um conjunto de normas regulatórias sobre a comercialização, o cultivo e o consumo de transgênicos. Em 2005, através da Lei n. 11.105/2005 ${ }^{38}$, foi criado o Conselho Nacional de Biossegurança (CNBS), instância máxima do processo decisório na área e que passou a articular a Comissão Técnica Nacional de Biossegurança (CTNBio), o MS, o MAPA e o MMA. Para os autores, uma das principais críticas ao trabalho do Conselho é a baixa participação da sociedade civil, o que dificulta a avaliação de maneira plural das implicações da liberação de transgênicos no país:

Uma das poucas certezas que se tem sobre a regulamentação dos alimentos transgênicos é que as normas não se baseiam em um princípio específico, e sim são pautadas na avaliação caso a caso, diferente dos Estados Unidos (EUA) e da União Europeia (UE), que têm seus princípios claramente adotados ${ }^{39}$.

Possíveis reações alérgicas e efeitos ligados à toxicidade dos alimentos geneticamente modificados tendem a ser pouco problematizados. Evidentemente, existem análises divergentes e controvérsias sobre os riscos envolvidos no consumo de transgênicos. Para Colli,

${ }^{36}$ CARNEIRO, F. F. (Org.) Dossiê Abrasco: um alerta sobre os impactos dos agrotóxicos na saúde. Rio de Janeiro: EPSJV; São Paulo: Expressão Popular, 2015. p. 79.

${ }^{37}$ CAMARA, M. C. C.; NODARI, R. O.; GUILAM, M. C. R. Regulamentação sobre bio(in)segurança no Brasil: a questão dos alimentos transgênicos. Interthesis, v. 10, n. 1, p. 261-285, 2013.

${ }^{38}$ BRASIL. Lei n. 11.105, de 24 de março de 2005. Regulamenta os incisos II, IV e V do $\S 1^{\circ}$ do art. 225 da Constituição Federal, estabelece normas de segurança e mecanismos de fiscalização de atividades que envolvam organismos geneticamente modificados - OGM e seus derivados, cria o Conselho Nacional de Biossegurança - CNBS, reestrutura a Comissão Técnica Nacional de Biossegurança - CTNBio, dispõe sobre a Política Nacional de Biossegurança - PNB, revoga a Lei $n^{\circ} 8.974$, de 5 de janeiro de 1995, e a Medida Provisória $n^{\circ}$ 2.191-9, de 23 de agosto de 2001, e os arts. $5^{\circ}, 6^{\circ}, 7^{\circ}, 8^{\circ}, 9^{\circ}, 10$ e 16 da Lei n 10.814, de 15 de dezembro de 2003, e dá outras providências. Disponível em: <http://www.planalto. gov.br/ccivil_03/_Ato2004-2006/2005/lei/L11105.htm>. Acesso em: 31 jan. 2017.

${ }^{39}$ CAMARA, M. C. C.; NODARI, R. O.; GUILAM, M. C. R. op. cit. p. 272. 
Mas, os produtos transgênicos que causam polêmica, por razões difíceis de compreender, são os alimentos. Os alimentos transgênicos são seguros e existem desde 1995. A exigência de regulamentações exageradas, com argumentos retóricos ao arrepio das evidências científicas, impõe o atraso aos países em desenvolvimento ${ }^{40}$.

No entanto, a criação de mecanismos de integração entre as perspectivas da saúde humana e preservação do meio ambiente e a liberação do consumo de alimentos de origem transgênica é urgente. O conflito entre os interesses privados e as demandas sociais na área é claramente percebido nos diferentes componentes do processo decisório em torno da regulação. A rotulagem desses alimentos, por exemplo, tem se revelado um verdadeiro campo de batalha e evidenciado os limites da efetiva implementação de normas e dispositivos legais. Ainda que o Brasil tenha avançado em marcos regulatórios, a debilidade dos mecanismos de fiscalização e a forte pressão do setor privado ameaçam a consolidação das conquistas. A notícia de que o plenário da Câmara dos Deputados aprovou em 28 de abril de 2015 o Projeto de Lei n. 4.148/2008 ${ }^{41}$ - que retira a exigência do símbolo “ $\mathrm{T}$ ” dos rótulos de alimentos com presença de organismos geneticamente modificados (OGMs) - parece sugerir que embates e tensões certamente permanecerão afetando o processo de regulamentação de alimentos no Brasil.

\section{Considerações finais}

De acordo com Vivero Pol, “[...] documentos e portarias oficiais recentes têm apontado um certo deslocamento das decisões técnicas tradicionais elaboradas pelos economistas para uma definição mais inclusiva de bens públicos"42 (tradução livre). A visão dos alimentos como mercadorias e bens privados a serem distribuídos de acordo com as leis da oferta e demanda tende a criar obstáculos para a consolidação da segurança alimentar e nutricional. Em contraste, a compreensão da dimensão coletiva do alimento e do direito humano à alimentaçäo saudável estimula o desenho e a implementação de acordos globais para a regulação da produção, a distribuição e a garantia de acesso aos alimentos. Sabemos que a

\footnotetext{
${ }^{40} \mathrm{COLLI}$, W. Organismos transgênicos no Brasil: regular ou desregular? Revista USP, São Paulo, n. 89, p. 148-173, mar./maio 2011. Disponível em: <http://rusp.scielo.br/pdf/rusp/n89/11.pdf>. p. 172. 29 Pol, José Luis Vivero Food as Commons : Reframing the Narrative of the Food System, April 23, 2013 available at SSRN ; http://ssm.com/abstract $=2255447$

${ }^{41}$ CÂMARA DOS DEPUTADOS. Projeto de Lei n. 4148/2008. Estabelece que os rótulos dos alimentos destinados ao consumo humano informem ao consumidor a natureza transgênica do alimento. Disponível em: <http:// www.camara.gov.br/proposicoesWeb/fichadetramitacao?idProposicao=412728>. Acesso em: 31 jan. 2017.

42،[...] recent documents and public statements indicate that policy makers are moving from the technical definition of a pure public good elaborated by economic theorists to a looser but more inclusive definition of the so-called impure public goods". VIVERO POL, José Luis. Food as commons: reframing the narrative of the food system. Apr. 23, 2013. Disponivel em: <https://papers.ssrn.com/sol3/papers.cfm?abstract_ id=2255447> $>$. 10.2139/ssrn.2255447. p. 15.
} 
alimentação e as práticas culinárias são parte indissociável da cultura dos povos e, portanto, integram as atividades cotidianas de maneira universal. Ao mesmo tempo, ainda que a dieta possa ser encarada como uma escolha privada, são inegáveis as repercussões dessa escolha nas condições de saúde da população. Como apontam Olufs e Schuman ${ }^{43}$, algumas características do sistema alimentar tendem a impor elevados custos sociais. Os impactos da produção de carne bovina no padrão climático global, na degradação do solo, na redução da biodiversidade e na proliferação de micro-organismos resistentes aos antibióticos são exemplos que iluminam a natureza coletiva da alimentação $0^{44}$. No entanto, a abordagem do alimento como um bem público ainda é extremamente controversa. Sem dúvida, economistas, nutricionistas, consumidores e empresas possuem visões distintas acerca da natureza das práticas alimentares, dos riscos envolvidos e do alcance das estruturas regulatórias. Há, porém, um razoável consenso entre especialistas e profissionais da área sobre a relevância das políticas públicas que buscam garantir a alimentação saudável através de práticas que respeitem a diversidade cultural, o meio ambiente e as necessidades singulares dos indivíduos e grupos sociais. De acordo com o GT "Indicadores e Monitoramento" do Consea, além de ser o maior comprador de agrotóxicos do mundo, o Brasil convive com o risco ainda não mensurável da liberação de sementes transgênicas, do consumo de alimentos com alto teor de sal, gordura e açúcar e, como desdobramento desse padrão alimentar, com o aumento de obesidade, diabetes e hipertensão arterial. Há, segundo o GT, uma diminuição expressiva no consumo de alimentos como arroz, feijão, peixe, hortaliças e frutas, combinada de maneira preocupante com o aumento do consumo de bebidas adoçadas e refeições prontas. No entanto, diferentemente do que ocorre em outros países onde existem instâncias públicas específicas e articuladas para monitorar a qualidade dos alimentos destinados à população, no Brasil há um conflito de competências entre os diferentes órgãos governamentais. Frequentemente não há clareza sobre os canais adequados para encaminhar as demandas e avaliar a efetividade das estratégias adotadas. De um lado, a infraestrutura necessária para implementar as ações regulatórias ainda é precária e falta maior articulação entre as diferentes agências que integram o sistema. Investimentos em laboratórios e qualificação de recursos humanos, aspectos cruciais para a detecção de possíveis contaminações e uso indevido de aditivos, assim como as demais ações de fiscalização não acompanham o crescimento das exigências na área. Por outro lado, há uma predominância do Poder Executivo na formulação de políticas regulatórias. Com isso, o papel das instituições representativas da sociedade é esvaziado - dificultando, dessa forma, a cooperação horizontal e consolidação de parcerias para a efetiva implementação do direito humano à alimentação saudável no país.

\footnotetext{
${ }^{43}$ OLUFS, Sid; SCHUMAN, David. The war against the common good. Washington: Chandler Sharp Publishers, 2006.

${ }^{44}$ WORLD HEALTH ORGANIZATION (WHO). Global public goods for health: the report of Working Group 2 of the Commission on Macroeconomics and Health, Geneva, 2002.
} 


\section{Referências}

ALVES FILHO, J. P. Uso de agrotóxicos no Brasil: controle social e interesses corporativos. São Paul: Annablume; FAPESP, 2002.

BELIK, W. Perspectivas para a segurança alimentar e nutricional no Brasil. Saúde e Sociedade, v. 12, n. 1, p. 12-20, jan./jun. 2003. Disponível em: <http://www.scielo.br/pdf/sausoc/v12n1/04.pdf . http://dx.doi.org/10.1590/S0104-12902003000100004.

BRASIL. Comitê Nacional para a Cúpula Mundial de Alimentação. Brasília. (DF): Ministério das Relações Exteriores; 1996. Disponível em: <http://www.fao.org/docrep/003/W3613P/ W3613P00.htm>. Acesso em: 02 ago. 2015.

BURLANDY, L. A construção da política de segurança alimentar e nutricional no Brasil: estratégias e desafios para a promoção da intersetorialidade no âmbito federal de governo. Ciên. e saúde coletiva, v. 14, n. 3, p. 851-860, jun. 2009. Disponível em: <http://www.scielo.br/scielo.php?script=sci_arttext \&pid=S1413-81232009000300020 >. http://dx.doi.org/10.1590/S1413-81232009000300020.

CAMARA, M. C. C.; NODARI, R. O.; GUILAM, M. C. R. Regulamentação sobre Bio(in) segurança no Brasil: a questão dos alimentos transgênicos. Interthesis, v. 10, n. 1, p. 261-285, 2013.

CARNEIRO, F. F. (Org.) Dossiê Abrasco: um alerta sobre os impactos dos agrotóxicos na saúde. Rio de Janeiro: EPSJV; São Paulo: Expressão Popular, 2015.

COLLI, W. Organismos transgênicos no Brasil: regular ou desregular? Revista USP, São Paulo, n. 89, p. 148-173, mar./maio 2011. Disponível em: <http://rusp.scielo.br/pdf/rusp/n89/11.pdf>.

CONSEA. Regulação de alimentos: garantia de segurança alimentar e nutricional. Texto elaborado pelo Grupo de Trabalho de Regulação de Alimentos Comissão Permanente 7-Consumo, Nutrição e Educação. Disponível em: <http://www4.planalto.gov.br/consea/ eventos/conferencias/5a-conferencia-nacional-de-seguranca-alimentar-e-nutricional/ documentos-da-5deg-conferencia/regulacao-de-alimentos.pdf $>$.

CONTRERAS CONTRERAS, Jesús. A modernidade alimentar: entre a superabundância e a insegurança. História, Questões e Debates, Curitiba, v. 54, p. 19-45, jan./jun. 2011.

COUTINHO, J. G.; RECINE, E. Experiências internacionais de regulamentação das alegações de saúde em rótulos de alimentos. Rev Panam Salud Publica, Pan Am J Public Health, v. 22, n. 6, 2007. Disponível em: <http://www.scielosp.org/pdf/rpsp/v22n6/a12v22n6.pdf>. http://dx.doi.org/10.1590/S1020-49892007001100012.

GILBERT, N. Transformation of the welfare state: the silent surrender of public responsability. New York: Oxford University Press, 2004.

HENRIQUES, P.; DIAS, P. C.; BURLANDY, L. A regulamentação da propaganda de alimentos no Brasil: convergências e conflitos de interesses. Cad. Saúde Pública, Rio de Janeiro, v. 30, n. 6, p. 1219-1228, jan./jun. 2014. <http://www.scielo.br/pdf/csp/v30n6/0102-311X-csp-30-6-1219.pdf>. http://dx.doi.org/10.1590/0102-311X00183912. 
HOUGHTON, J. R.; ROWE, G; FREWER, L. J.; KLEEF, E.V.; CHRYSSOCHOIDIS, G; KEHAGIA, O.; KORZEN-BOHR, S.; LASSEN, J.; PFENNING, U.; STRADA, A. The quality of food risk management in Europe:perspectives and priorities. Food Policy, v. 33, p. 13-26, 2008.

KINGDOM, J.W. Agendas, alternatives and public choices. New York: Longman, 2003.

L'ABBATE, S As políticas de alimentação e nutrição no Brasil: I. Período de 1940 a 1964. Revista Nutrição PUCCAMP, v. 1, n. 2, p. 87-138, jul./dez. 1988.

LANG, T; HEASMAN, M. Food wars: the global battle for mouths, minds and markets. London: Earthscan, 2005.

LINDBLOM, C. E.; WOODEHOUSE, E. J. The policy: making process. New Jersey: Prentice Hall, 1993.

MAGALHÃES, R. Enfrentando a pobreza, reconstruindo vínculos sociais: as lições da Ação da Cidadania contra a Fome, a Miséria e pela Vida. Cad Saude Pública, Rio de Janeiro, v. 18, suppl., p. 121-137, 2002. Disponível em: <http://www.scielo.br/pdf/csp/v18s0/13799.pdf>. http://dx.doi.org/10.1590/S0102-311X2002000700013.

Fome: uma (re)leitura de Josué de Castro. Rio de Janeiro: Fiocruz,1997.

MARTINS, A. P. B.; ANDRADE, G. C.; BANDONI, D. H. Avaliação do monitoramento do teor de sódio em alimentos: uma análise comparativa com as metas de redução voluntárias no Brasil. Revista Visa em Debate, v. 3, n. 2, p. 56-64, 2015. Disponível em: $<$ https://visaemdebate.incqs.fiocruz.br/index.php/visaemdebate/article/view/323/218>. DOI: $10.3395 / 2317-269 x .00323$.

(Org.). Publicidade de alimentos não saudáveis: os entraves e as perspectivas de regulação no Brasil. São Paulo: Instituto Brasileiro de Defesa do Consumidor - Idec, 2014. (Cadernos Idec - Série Alimentos, v. 2).

OLUFS, Sid; SCHUMAN, David. The war against the common good. Washington: Chandler Sharp Publishers, 2006.

PROENÇA, R. P. da C.; SILVEIRA, B. M. Recomendações de ingestão e rotulagem de gordura trans em alimentos industrializados brasileiros: análise de documentos oficiais. Rev. Saúde Pública, São Paulo, v. 46, n. 5, out. 2012. Disponível em: <http://www.scielo.br/pdf/rsp/ v46n5/20.pdf>. http://dx.doi.org/10.1590/S0034-89102012000500020.

ROSANVALLON, P. La nouvelle question sociale: repenser l'etat-providence. Paris: Éditions du Seuil, 1995.

SEN, A. Poverty and famines. New York: Oxford University Press, 1997.

SILVA, Alberto Carvalho da. De Vargas a Itamar: políticas e programas de alimentação e nutrição. Estudos Avançados, São Paulo, v. 9, n. 23, jan./abr. 1995. Disponível em: <http://www. scielo.br/pdf/ea/v9n23/v9n23a07.pdf >. http://dx.doi.org/10.1590/S0103-40141995000100007. 
SOUZA, C. Estado da arte da pesquisa em políticas públicas. In: HOCHMAN, G.; ARRETCHE, M.; MARQUES, E. (Orgs.). Políticas públicas no Brasil. Rio de Janeiro: Fiocruz, 2007. p. 65-86.

VIVERO POL, José Luis. Food as commons: reframing the narrative of the food system. Apr. 23, 2013. Disponível em: <http://ssm.com/abstract=2255447>. 10.2139/ssrn.2255447.

WORLD HEALTH ORGANIZATION (WHO). Food and health in Europe: a new basis for action. WHO Regional Publications, European Series n. 86, 2004.

Global public goods for health: the report of Working Group 2 of the Commission on Macroeconomics and Health, Geneva, 2002.

Rosana Magalhães - Doutora em Saúde Coletiva pela Universidade do Estado do Rio de Janeiro; mestre em Saúde Pública pela Escola Nacional de Saúde Pública (ENSP), Fundação Oswaldo Cruz; graduada em Nutrição pela Universidade Federal do Rio de Janeiro. Pesquisadora titular do Departamento de Ciências Sociais da ENSP, Fundação Oswaldo Cruz. Rio de Janeiro/RJ, Brasil. E-mail : rosana99@uol.com.br. 